\title{
Formação de um mundo já posto: Kohlhaas e sua sanha justiceiro-vingativa
}

\section{Rodrigo Campos de Paiva Castro*}

\begin{abstract}
The main character in Kleist's "Michael Kohlhaas" novella sacrifices himself in order to guarantee his survival. Nonetheless, as the reader will eventually notice, his fight produces no new reality at all, but only reaffirms a law that was already in force. A magic and natural law wich will send him on a journey of vengeance and justice. At the end of it, the man who laboured to ratify himself as an autonomous subject ends up serving as an object. But the result will be as well one of confirmation from the order wich gave birth to this subject. A strange order where contradictory elements (rule of law/lawlessness; violence/peace; justice/injustice; myth/history; heaven/hell; etc.) affirm themselves mutually.
\end{abstract}

Keywords: Kleist; Kohlhaas; Vengeance; Justice

Zusammenfassung: Die Hauptfigur der kleistschen Novelle "Michael Kohlhaas" bemüht sich mit allen ihren Kräften ihr Weiterleben zu gewährleisten. Wie der Leser aber früher oder später bemerken wird, bringt ihr Kampf keine neue Ordnung, sondern bestätigt wieder ein Gesetz, das schon gültig war. Ein zauberisches und natürliches Gesetz, dass die Hauptfigur auf eine von Rache und Gerechtigkeit geprägte Reise senden wird. Am Schluss dieser Reise, offenbart sich der Mann, der ein selbstständiges Subjekt sein wollte, als ein bloßes Objekt. Aber das Ergebnis zeigt sich auch als eine Bekräftigung der Ordnung, die dieses Subjekt auf die Welt gebracht hat. Eine merkwürdige Ordnung, wo widersprüchliche Elemente (Ordnung/Unordnung; Gewalt/Frieden; Gerechtigkeit/Ungerechtigkeit; Mythos/Geschichte; Himmel/Hölle; usw.) sich gegenseitig bestätigen.

Stichwörter: Kleist; Kohlhaas; Rache; Gerechtigkeit

"Michael Kohlhaas", publicada em sua versão definitiva no ano de 1810, é a novela mais importante e mais longa de Heinrich von Kleist. Como acontece com o restante da produção do autor, esse texto também deu origem a uma gama imensa e variadíssima de interpretações, muitas delas abertamente conflitantes, mas, o que é estranho, não necessariamente excludentes. Este artigo discorre sobre essa característica mágico-natural do texto kleistiano, fazendo-o a partir dos esforços justiceiro-vingativos de Kohlhaas.

O protagonista é um negociante de cavalos, um membro da burguesia. Kohlhaas representa a "classe móvel" por excelência, a citada burguesia, classe

\footnotetext{
*Mestre em Literatrua Alemã pela Universidade de São Paulo. rodrigocpcastro@gmail.com
} 
cuja ascensão acompanha o desaparecimento do petrificado mundo feudal, marcado pela divisão da sociedade em camadas estanques, e classe que faz dos esforços de ascensão uma de suas pedras de toque ${ }^{1}$. Na novela, que descreve um embate dessa burguesia nascente com a nobreza decadente sob a ótica de um narrador do século 18/19 (quando a vitória da classe em ascensão já estava decidida, mas, na Alemanha, ainda não sedimentada), o patrimônio do comerciante, na forma de cavalos e na forma de títulos, vive a percorrer as propriedades da nobreza. Enquanto os nobres estão aferrados a suas terras, cujo controle lhes garante o prestígio e o poder, Kohlhaas vê-se livre para cogitar e realizar vários périplos.

A mobilidade é uma das marcas do sujeito moderno. Pense-se em $O s$ anos de peregrinação de Wilhelm Meister ${ }^{2}$ ou, talvez de forma mais típica, em $A$ História Maravilhosa de Peter Schlemihl - o personagem de Chamisso passa grande parte de sua vida correndo mundo calçado com as botas de sete léguas $^{3}$. No caso do comerciante de Kleist, não se trata de garantir apenas seu ir-e-vir, mas também, ou principalmente, o ir-e-vir das mercadorias. Assim se compreende por que o comerciante insistirá, em todas as vezes que apresenta suas exigências, na reposição dos cavalos a seu estado original. Uma exigência certamente estranha para um mercador comum, que ficaria satisfeito com uma indenização em dinheiro. Kohlhaas, porém, é um comerciante radical, desenraizado do mundo e das pessoas que o cercam, mas profundamente enraizado nos princípios que garantem a constituição de sua subjetividade. A fim de fazer os cavalos circularem novamente, é preciso que a parelha seja o que já não é mais, mas que foi um dia quando ele a conduzia ao mercado de Leipzig ${ }^{4}$. Além das "fronteiras abertas", a circulação de mercadorias necessita, para que aconteça, do respeito à propriedade privada ${ }^{5}$. Essa circulação não se dá somente no périplo dos produtos pelos espaços físicos, mas na sua errância de um proprietário para outro. Uma mercadoria pode circular sem sair do

\footnotetext{
${ }^{1}$ Os esforços de ascensão social espelham o comportamento característico do narrador: impor limites para superá-los. É impossível ascender socialmente em um mundo igualitário. Para uma análise mais aprofundada desse narrador ímpar, ver minha dissertação de mestrado Michael Koblhaas - a vitória da derrota

${ }^{2}$ Que, diga-se de passagem, já peregrinara nos "anos do aprendizado".

3 O livro não se dedica a descrever essas errâncias do personagem, mas, segundo se deduz, tal período de viagens constantes é o que toma a maior parte de sua vida.

${ }^{4}$ Quando o comerciante reencontra os cavalos estropiados dentro de um dos estábulos de Tronkenburgo, bate neles para mostrar ao castelão que, de tão debilitados, eles não conseguiam se mexer. "Er [Kohlhaas] [...] versuchte, die erschöpften Gaule durch einen Gertenstreich zu erregen, und zeigte ihm [dem Schlossvogt], dass sie sich nicht rührten" (KLEIST 2005: 23); "Ele [Kohlhaas] [...] tentou incitar os extenuados cavalos por meio de um golpe de chibata, e monstrou-lhe [ao castelão], que eles não se mexiam" - todas as traduções constantes deste artigo foram feitas por mim.

5 "Es geht also nicht mehr um das Eigentumsrecht an den beiden Rappen, sondern um die Bedingung der Möglichkeit von Eigentum unbedingt" (KITTLER 1987: 308); "Não se trata mais, portanto, do direito de propriedade sobre os dois cavalos, mas da condição absoluta da possibilidade da propriedade".
} 
lugar; para isso, basta que troque de dono. "Livre mercado" e "respeito à propriedade privada": esses são dois pilares do "liberalismo", doutrina cuja defesa forma uma das linhas de força da novela "Michael Kohlhaas".

Quando o senhor feudal Wenzel von Tronka e seus comandados apreendem a parelha sob um falso pretexto, não provocam apenas um prejuízo para Kohlhaas, que deixou de vender os cavalos e depois teria de arcar com o gasto de recuperá-los, mas investem contra o âmago desse sujeito. $\mathrm{O}$ confisco dos animais e sua posterior dilapidação não significam somente um eventual revés comercial a ser inscrito na coluna de "saída" do livro-caixa do comerciante, mas ameaçam-no em sua dimensão existencial ${ }^{6}$. O fato de o comércio ser o fundamento da personalidade kohlhaasiana não significa, porém, que seja pelo comércio em si que o mercador lutará. Ou, o comércio, quando transformado em móvel principal de um determinado sujeito, implanta em seu íntimo o princípio que faz do comércio o comércio: acumular capital trocando mercadorias que se equiparam apesar de dotadas das qualidades as mais diversas, equiparar as mercadorias, portanto, através de seu valor de troca. Em termos mais técnicos, a valorização do valor abstrato. Toda a discussão sobre a mobilidade-imobilidade que se tenta apresentar neste texto não deve ser vista, assim, apenas nessa sua superfície propriamente "espacial" (ou patrimonial e social). Por debaixo dela, corre seu motor, a lógica amalucada das coisas transformadas em mercadorias, uma lógica fluida, mas petrificada, capaz de abarcar os mais diferentes conteúdos, a fim de subsumilos à mesma medida. Tanto é assim que o próprio narrador dirá: "para ele [Kohlhaas] não se tratava dos cavalos - ele teria sentido a mesma dor se isso envolvesse um par de cães"7. A defesa da propriedade privada e a defesa do livre trânsito das mercadorias inscrevem-se, nesse cenário, como epifenômenos do princípio da valorização do valor abstrato, princípio esse descrito nos termos kleistianos como "obstinação errática" ("seines rasenden

\footnotetext{
6 "Schon gar nicht geht es [das Geschäft der Rache] allein um den materiellen Wert der Pferde, sondern um sein [Kohlhaas'] und seiner Mitbürger Dasein als Mensch" (MÜLLER-SEIDEL 1961: 109); "Já isso [o negócio da vingança] não gira apenas em torno do valor material dos cavalos, mas sim em torno da existência dele [de Kohlhaas] e de seus concidadãos como seres humanos"; "Dieser Vorgang [die Bemühung um die Wiederherstellung der Rappen noch vor der gewalttätigen Aktionen] macht deutlich, dass es nicht um materiellen Verlust, sondern um die Integrität der Personen geht" (KRETZSCHMAR 1993: 25); "Esse evento [a luta pela recuperação dos murzelos ainda antes das ações violentas] torna claro que isso não gira em torno das perdas materiais, mas em torno da integridade das pessoas"; "Insofern ist von der Schilderung [des ersten Konflikt] des Streitfalls her völlig klar, dass es nicht lediglich um die beiden Rappen geht, sondern dass Kohlhaas' bürgerliche Existenz auf dem Spiel steht" (FISCHER-LiCHTE 1991: 32); "Conforme mostra claramente a apresentação [do conflito inicial] da disputa, não se trata apenas dos dois cavalos, mas do fato de a existência de Kohlhaas como cidadão estar em jogo".

7 "[Kohlhaas], dem es nicht um die Pferde zu tun war - er hätte gleichen Schmerz empfunden, wenn es ein Paar Hunde gegolten hätte" (KLEIST 2005: 47).
} 
Starrsinns" ${ }^{\prime \prime}$. No peito de Kohlhaas, palpita o coração exangue dessa lei, coração esse que o comerciante, para mantê-lo a bombear, precisa dividir com o mundo: é impossível ser mercador sozinho?.

A "perda" dos cavalos, como ficou dito, não abala Kohlhaas por conta do prejuízo que implica. A maior preocupação do comerciante não será propriamente recuperar seus animais, mas convencer o mundo, todo mundo, a reconhecer a necessidade de que seus cavalos sejam recuperados sob a responsabilidade de Wenzel von Tronka. A necessidade imperiosa de inculcar os que o cercam de seus valores, e Kohlhaas chega a literalmente abrir a cabeça de um de seus supostos opositores na primeira das investidas militares, explica o comportamento sóbrio do comerciante quando este se depara com os abusos iniciais realizados em Tronkenburgo e explica a forma "radical" com que agirá ao recusar, no regresso ao castelo, arcar com o prejuízo. Para sustentar seu caso, caberia a Kohlhaas argumentar, em Tronkenburgo e nos tribunais, que, frente ao fato documentalmente comprovado da posse ilegal dos animais, era de responsabilidade dos dirigentes do castelo zelar pelo bemestar deles, o que não aconteceu. Mas, para o comerciante, não basta exigir de seus adversários a indenização (em dinheiro ou em espécie) a que faz jus. Interessa, isso sim, convencê-los de que seus direitos de ir-e-vir com os cavalos e de propriedade sobre os cavalos, ou simplesmente, o direito de ir-evir da mercadoria cavalos, não podem ser desrespeitados. Nas duas vezes, durante a cena inicial em Tronkenburgo, na qual o comerciante cogita arcar com o prejuízo ou vacila, chega alguém a quem tentará convencer ${ }^{10}$. Kohlhaas até aceitaria levar para sua quinta os animais no estado em que estavam, mas retrocede sempre que a diferença de opinião salta aos olhos. Essa postura do

\footnotetext{
8 "zur blossen Befriedigung seines rasenden Starrsinns" (KLEIST 2005: 98); "para a mera satisfação de sua obstinação errática". O adjetivo "rasend" significa "furioso", "colérico", mas também "frenético", "agitado", "errático". A expressão "rasender Starrsinn", conforme observa FÖLDÉNYI, conjuga em si elementos paradoxais, algo típico dessa prosa: "Die gleichen Sätze, die durch unendliche Genauigkeit, Umständlichkeit und Kühle geprägt sind, sind auch abgehackt, zerrissen, hektisch und fiebrig. Sie stehen und rasen zur gleichen Zeit - der gleiche 'rasende Starrsinn' kennzeichnet sie wie Kohlhaas" (FÖLDÉNYI 1999: 373); "As mesmas frases que são marcadas por uma infinita exatidão, formalidade e sobriedade, são também fraturadas, rasgadas, hécticas e febris. Elas, ao mesmo tempo, permanecem e correm - a mesma 'obstinação errática' que marca Kohlhaas as marca"; itálicos no original.

${ }^{9}$ A fim de mercadejar, é preciso que haja de quem comprar e para quem vender.

${ }^{10}$ Primeiro, quando Kohlhaas pensava em sair de Tronkenburgo com os cavalos do jeito que estavam, chega o castelão: "Kohlhaas [...] machte schon, da doch nichts anders übrig blieb, Anstalten, das Raubnest mit den Pferden nur wieder zu verlassen, als der Schlossvogt, von dem Wortwechsel herbeigerufen, erschien" (KLEIST 2005: 23); "Kohlhaas [...] já fazia menção, pois que nada mais havia a fazer, de partir novamente do ninho de ladrões apenas com os cavalos, quando o castelão, atraído pela troca de palavras, apareceu". Depois, quando o comerciante medita sobre o que fazer, chega Wenzel von Tronka: "Er stand noch [...] und sann, was in seiner Lage zu tun sei, als sich die Szene plötzlich änderte, und der Junker Wenzel von Tronka [...] in den Schlossplatz sprengte" (KLEIST 2005: 25); "Ele continuava em pé e meditava, sobre o que, na posição em que estava, deveria fazer, quando a cena alterou-se repentinamente, e o senhor feudal Wenzel von Tronka rompeu no pátio do castelo".
} 
comerciante explica por que, em meio ao diálogo com o castelão, seu "sentimento de justiça, que equivalia a uma balança de pesar ouro, ainda vacilava" ("Rechtgefühl, das einer Goldwaage glich, wankte noch"11) e por que ele não tem certeza sobre "a culpa de seus oponentes" ${ }^{12}$. Nesse momento, de posse da já citada declaração judicial, o comerciante tem certeza da culpa de seus oponentes quanto à apreensão injusta dos animais e a conseqüente obrigação deles de indenizá-lo. O próprio narrador dirá isso, nos parágrafos seguintes, textualmente $^{13}$. O que o comerciante não tem é a certeza sobre todo o cenário em que se desenrolou o desgaste dos cavalos, algo de que precisa saber para conseguir convencer seus adversários sobre a necessidade de que os cavalos sejam recuperados a seu estado inicial a fim de continuarem circulando ${ }^{14}$. Kohlhaas comporta-se não como um cidadão que se serve das leis para proteger seus direitos, mas como um homem tomado pela missão de convencer o mundo de seus argumentos. O raciocínio estritamente jurídico não atende à demanda total do comerciante. Em nome dessa missão, tudo o mais se torna acessório.

O esforço de convencimento continuará a ser perseguido ao longo de toda a novela e dará bons frutos, mesmo que esse convencimento aconteça por meio do necessário mergulho no exercício arbitrário da força. Pertencem às tentativas de submeter o mundo a suas idéias, tentativas essas de formação do mundo ${ }^{15}$, tanto a postura "argumentativa" que Kohlhaas adota nos diálogos com os integrantes de Tronkenburgo quanto as manobras políticojurídicas a que recorre para atrair a sua órbita de valores as instâncias do poder. Também se incluem nessa missão os mandatos expedidos por

\footnotetext{
11 (KLEIST 2005: 25).

12 "[...] er [Kohlhaas] war, vor der Schranke seiner eigenen Brust, noch nicht gewiss, ob eine Schuld seinen Gegner drücke" (KLEIST 2005: 25); "[...] ele [Kohlhaas] ainda não estava certo, diante do foro judicial de seu próprio peito, sobre se a culpa pesava sobre seus oponentes".

13 "Die Rechtssache war in der Tat klar. Der Umstand, dass die Pferde gesetzwidriger Weise festgehalten worden waren, warf ein entscheidendes Licht auf alles übrige; und selbst wenn man hätte annehmen wollen, dass die Pferde durch einen blossen Zufall erkrankt wären, so würde die Forderung des Rosskamms, sie ihm gesund wieder zuzustellen, noch gerecht gewesen sein" (KLEIST 2005: 39); "A questão jurídica era, em verdade, clara. A circunstância, de que os cavalos foram apreendidos de forma ilegal, atirava uma luz decisiva sobre todo o restante; e mesmo se se quisesse pressupor que os cavalos teriam adoecido devido a um mero acaso, a exigência do magano de cavalos, de que eles lhe fossem entregues de volta saudáveis, ainda assim seria justa".

$14 \mathrm{O}$ comerciante teria aberto mão do valor referente aos cavalos para simplesmente ter Herse a seu lado, naquele momento, e poder verificar a veracidade da narrativa do castelão. "Kohlhaas hätte den Wert der Pferde darum gegeben, wenn er den Knecht [Herse] zur Hand gehabt, und dessen Aussage mit der Aussage dieses dickmäuligen Burgvogts hätte vergleichen können" (KLEIST 2005: 25); "Kohlhaas teria dado o valor dos cavalos por isso, para ter o criado [Herse] à mão e poder comparar as declarações deste com as declarações desse castelão gabarolas".

15 "Und deshalb muss man nicht das Gesetz von der Welt einfordern, sondern die Welt selbst im Sinne dieser Gesetzes umformen" (FÖLDÉNYI 1999: 346); "E por isso não se deve solicitar a lei do mundo, mas transformar o próprio mundo segundo determina essa lei".
} 
Kohlhaas, nos quais mescla relatos sobre o que lhe ocorreu com acusações contra Wenzel von Tronka e declarações sobre a fundação de uma nova ordem, e, de forma destacada, o diálogo travado com Lutero - Kohlhaas devota grande respeito ao homem que fundou a religião responsável por atribuir "um significado religioso ao trabalho secular cotidiano"16, religião essa a que tinha se convertido havia pouco ${ }^{17}$.

Os esforços do comerciante para convencer Lutero sobre seu caráter justo entrelaçam-se com os esforços para a obtenção do "passe livre", com o qual poderia ir a Dresden retomar o processo judicial. No diálogo com o clérigo, mais uma vez, Kohlhaas não menciona a irregularidade envolvida na apreensão dos cavalos e a conseqüente responsabilidade do senhor feudal de Tronkenburgo por indenizá-lo. O direito dele à indenização é líquido e certo, não apenas para o próprio mercador, mas também para Lutero, para os demais representantes da nobreza e, não menos, para o narrador, que antecipara, antes que o próprio comerciante pudesse sabê-lo, o juízo favorável a respeito da pretensão de Kohlhaas $^{18}$. E o comerciante tampouco tenta rebater as acusações, feitas no folheto assinado pelo clérigo, de que havia abusado da violência, portando-se como o "lobo do deserto"19. Adotando uma postura equilibrada como em Tronkenburgo e suportando os ataques verbais da parte do clérigo, Kohlhaas apresenta argumentos que se resumem a dois pontos: a recusa da lei em corroborar sua exigência de ver Wenzel von Tronka responsabilizado pela recuperação de seus cavalos o atirara para fora do mundo ${ }^{20}$; se isso não se deu desse modo, que Lutero lhe obtenha o "passe livre" a fim de que possa, em Dresden, convencer a nobreza de que sua pretensão deve ser atendida. Sem um Estado garantidor da propriedade

\footnotetext{
16 (WeBER 2001: 64). A defesa do trabalho como categoria ontológica de inserção do indivíduo na sociedade moderna também explica o caráter missionário da contenda kohlhaasiana. Em nome desse trabalho ("Beruf", em alemão, palavra derivada do verbo "berufen", chamar), o comerciante fará de tudo. Segundo o calvinismo (uma vertente do protestantismo), o patrimônio do cristão acumulado por obra do trabalho lhe garantiria um lugar no céu. "As obras do homem servirão apenas à graça de Deus e serão a materialização da 'fé eficaz' que faz do crente um dentre os salvos - a certeza de pertencer à legião dos agraciados exerce-se por meio das obras, o que leva o calvinista a uma ação ascética - a ação é indispensável como sinal da escolha. O calvinista assim cria a convicção de sua salvação" (WEBER 2001: 99). Kohlhaas, seguindo o padrão de exagero que caracteriza essa prosa, seria não apenas luterano, mas um luterano "radical", ou, em outros termos, um calvinista.

17 "lutherischer Religion (zu welchem eben damals aufkeimenden Glauben sie [Lisbeth] sich, nach dem Beispiel ihres Mannes, bekannt hatte)" (KLEIST 2005: 59); "religião luterana (crença justamente então em expansão a qual ela, seguindo o exemplo de seu homem, havia se convertido)".

18 "diese ungesetzlichen Erpressungen" (KLEIST 2005: 17); "essas extorsões ilegais". O narrador reforça esse juízo alguns parágrafos à frente, conforme nota 13.

19 "Wolf der Wüste" (KLEIST 2005: 75).

20 "Der Krieg, den ich mit der Gemeinheit der Menschen führe, ist eine Missetat, sobald ich aus ihr nicht, wie Ihr mir die Versicherung gegeben habt, verstossen war!" (KLEIST 2005: 78); "A guerra, que eu travo com a comunidade dos homens, é um crime se eu não tivesse sido, como vós me garantistes, dela expulso!".
} 
privada e da livre circulação das mercadorias, Kohlhaas não pode existir ${ }^{21}$. De outro lado, será parte dos esforços vitais desse comerciante, impreterivelmente "liberal", entrar em conflito com os poderes "estatais" ao transitar com suas mercadorias, o mais livremente possível, pelas diferentes fronteiras e ao impor a respeito de suas mercadorias, o mais rigidamente possível, barreiras à ingerência "estatal" sobre a propriedade privada. Quando esse jogo de regras auto-revogatórias atingir paroxismos insustentáveis, seja pela presença abusiva do Estado, como se dá quando o "privilégio senhorial" de Wenzel von Tronka estropia os cavalos, ou pela ausência total do Estado, como se dá quando fracassam os esforços no âmbito judicial, resta a Kohlhaas tomar as rédeas do poder e fundar uma "nova ordem", uma "nova ordem", no entanto, peculiar.

Os mandatos expedidos pelo comerciante anunciam verbalmente a criação de uma "nova ordem", mas funcionam antes como instrumentos para inscrever no mundo medieval um recurso típico dos Estados modernos, o estado de exceção, fundando, nesse sentido, um Estado reformado. Já no primeiro desses documentos, Kohlhaas coloca-se na posição de uma autoridade governamental, expedindo uma "intimação judicial" para que Wenzel von Tronka compareça a Kohlhaasenbrück a fim de engordar os cavalos $^{22}$. O documento joga por terra a distinção entre poderes legislativo, executivo e judiciário, fazendo de Kohlhaas promulgador, intérprete e executor da lei (passados os três dias, o comerciante atacará o castelo a fim de buscar Wenzel von Tronka). Essa indefinição quanto às competências de cada um dos três poderes é uma das marcas do estado de exceção ${ }^{23}$ e perdurará enquanto o comerciante não conseguir permissão para ir a Dresden defender seu caso. No terceiro mandato, Kohlhaas declara-se "um senhor desprovido

\footnotetext{
21 O trecho consta também do diálogo com Lutero: "[Lutero pergunta:] Wer hätte dich aus der Gemeinschaft des Staats, in welchem du lebtest, verstossen? [...] Verstossen, antwortete Kohlhaas, [...] nenne ich den, dem der Schutz der Gesetze versagt ist! Denn dieses Schutzes, zum Gedeihen meines friedlichen Gewerbes, bedarf ich; ja, er ist es, dessenhalb ich mich, mit dem Kreis dessen, was ich erworben, in diese Gemeinschaft flüchte" (KLEIST 2005: 78); "[Lutero pergunta:] Quem te teria expulsado da comunidade do Estado no qual tu vives? [...] Expulso, respondeu Kohlhaas, [...] eu considero aqueles aos quais é negada a proteção da lei! Porque eu preciso dessa proteção para a prosperidade do meu pacífico negócio; sim, é por isso, devido a essa proteção é que eu, com o conjunto do que conquistei, refugiei-me nessa comunidade".

22 "Er [Kohlhaas] setzte sich nieder und verfasste einen Rechtsschluss, in welchem er den Junker Wenzel von Tronka, kraft der ihm angebotenen Macht, verdammte, die Rappen, die er ihm abgenommen, und auf den Feldern zu Grunde gerichtet, binnen drei Tagen nach Sicht, nach Kohlhaasenbrück zu führen, und in Person in seinen Ställen dick zu füttern" (KLEIST 2005: 61); "Ele [Kohlhaas] sentou-se e redigiu uma intimação judicial, na qual ele condenava Wenzel von Tronka, por força do poder a ele conferido, a, dentro de três dias, levar os cavalos, que ele lhe tirou e que arruinou nos campos, para Kohlhaasenbrück e, pessoalmente, em seus estábulos, engordá-los".

23 "Uma das características essenciais do estado de exceção - a abolição provisória da distinção entre poder legislativo, executivo e judiciário [...]" (AGAMBEN 2003: 19).
} 
de país e mundo, sujeito apenas a Deus"24; no quinto, se autonomeará um "representante de Miguel, o arcanjo"25. O ordenamento jurídico "regular" suspende-se, mas para o fim declarado de punir o senhor feudal e os que se colocarem ao lado dele ${ }^{26}$. Já a partir do primeiro mandato, não se poderá mais distinguir entre a justiça (cuja remissão é à esfera pública dos valores que garantem a igualdade entre os homens) e a vingança (cuja remissão é à esfera privada do sentimento de ódio). A confusão entre esfera pública e privada é um dos temas principais da novela, e a luta de Kohlhaas passará pelos esforços para traçar limites entre essas duas ordens. No entanto, o comerciante o faz recorrendo a uma zona cinzenta na qual as duas confundem-se de forma inextrincável.

O estado de exceção desaparece, num estalar dos dedos, quando Kohlhaas recebe o "passe livre". A passagem de um extremo a outro, da exceção à ordem, faz-se de forma assim natural porque, no fundo, não há uma oposição plena entre um pólo e outro. O comerciante recorre à suspensão da ordem para afirmar a ordem ${ }^{27}$, recorre à anomalia para garantir o nomos. No processo, moderniza o "mundo feudal" facultando-lhe a via da exceção. O instituto paradoxal da suspensão do ordenamento jurídico para assegurar a manutenção desse próprio ordenamento comparece às Constituições dos Estados modernos, mas está ausente como tal do "mundo medieval"28. Na campanha militar que realiza e nos mandatos que expede, Kohlhaas nunca se comporta como um verdadeiro revolucionário interessado em depor a ordem estatuída e fundar uma ordem mais justa ${ }^{29}$. A luta do comerciante se resumirá à luta por convencer o mundo de que a lei já posta (a referida lei da

\footnotetext{
24 "In einem anderen Mandat, das bald darauf erschien, nannte er [Kohlhaas] sich: 'einen Reichs- und Weltfreien, Gott allein unterworfenen Herrn"' (KLEIST 2005: 68); "Em um outro mandato, surgido pouco depois disso, ele [Kohlhaas] nomeou-se: 'um senhor desprovido de país e mundo, sujeito apenas a Deus"'.

25 Para o original em alemão do trecho, ver nota seguinte.

26 "Er [Kohlhaas] nannte sich [...] 'einen Statthalter Michaels, des Erzengels, der gekommen sei, an allen, die in dieser Streitsache des Junkers Partei ergreifen würden, mit Feuer und Schwert, die Arglist, in welcher die ganze Welt versunken sei, zu bestrafen"" (KLEIST 2005: 73); "Ele [Kohlhaas] nomeou-se [...] 'um representante de Miguel, o arcanjo, que teria vindo para, com ferro e fogo, punir, quanto a todos que ficassem ao lado do senhor feudal nessa disputa, a maldade na qual o mundo todo teria mergulhado"'.

27 Ainda segundo AgAmBEN, o "soberano, através do estado de exceção, 'cria e garante a situação', da qual o direito tem necessidade para a própria vigência" (AGAMBEN 2003: 25).

28 "A exceção medieval representa, nesse sentido, uma abertura do sistema jurídico a um fato externo, uma espécie de fictio legis pela qual, no caso, se age como se a escolha do bispo [o exemplo de exceção medieval citado diz respeito à possibilidade de a Igreja reconhecer a qualidade de bispo a uma pessoa que, mesmo impossibilitada de ser ordenada como tal, o foi] tivesse sido legítima. O estado de exceção moderno é, ao contrário, uma tentativa de incluir na ordem jurídica a própria exceção, criando uma zona de indiferenciação em que fato e direito coincidem" (AGAMBEN 2003: 42); "A idéia de que a suspensão do direito pode ser benéfica ao bem comum é estranha ao mundo medieval" (AGAMBEN 2003: 42).

29 "Aus Kohlhaas' Rachefeldzug wird keine Revolution" (FISCHER-LiCHTE 1991: 35); "Da campanha de vingança de Kohlhaas não resulta nenhuma revolução".
} 
valorização do valor) não pode ser infringida ${ }^{30}$. Tudo o mais nesse embate será acessório.

Também será acessória para a sanha justiceiro-vingativa de Kohlhaas a morte de sua mulher. Parte importante da crítica kleistiana tenta fundar nesse episódio o móvel das ações de Kohlhaas. Quando o comerciante aceita a ida de Lisbeth a Brandenburgo (onde ela morreria) com o desígnio de que a mulher sirva-se dos favores do castelão do príncipe eleitor dessa região para fazer o pleito jurídico de Kohlhaas chegar diretamente às mãos do mandatário, já havia decidido lançar-se com violência contra Wenzel von Tronka e o ordenamento que o protegia ${ }^{31}$. Kohlhaas já vacilara perante o "foro judicial de seu peito", mas isso apenas porque precisava antes dominar todos os elementos envolvidos no episódio da apreensão dos cavalos a fim de partir rumo a sua cruzada argumentativa. Fracassados os esforços de convencimento por meio do discurso, o comerciante recorre à guerra total. Nada, nem mesmo a eventual morte da mulher ou o plano dela de reencontrar-se com um homem que, no passado, a cortejara, poderá afastá-lo dessa sanha ${ }^{32}$.

O momento da virada, o rompimento da barreira rumo ao estado de exceção identificado acima, dá-se não quando da perda de Lisbeth, mas quando o comerciante recebe a segunda das três decisões desfavoráveis a respeito de seu caso, decisão essa que possui caráter definitivo em vista das poucas chances de sucesso do plano acalentado por Kohlhaas de ir a Brandenburgo falar pessoalmente com o príncipe eleitor. É depois dessa sentença que Kohlhaas se afastará da mulher e dos filhos e que não terá mais alegria com os negócios; é depois dela que sela o contrato com o juiz e que dá ordens de enviar sua família para além-fronteiras; é nesse momento que se prepara para, sem grandes esperanças, realizar uma tentativa final de entregar pessoalmente, ao príncipe eleitor de Brandenburgo, a petição de seu caso. A guerra, porém, já está selada e só não eclode imediatamente por conta da derradeira manobra, que será realizada, no lugar dele, por Lisbeth. Kohlhaas, de toda forma, já se decidiu por pegar em armas, por fazer "justiça" com as próprias mãos e se vingar.

\footnotetext{
30 "Der Aufstand des Rosshändlers gilt also nicht als einer Änderung der Verhältnisse, sondern der Offenbarmachung verdeckter Sachverhalte" (IDE 1965: 33); "O levante do comerciante de cavalos não equivale, portanto, a uma mudança das relações, mas à revelação das circunstâncias ocultas".

31 Para uma fundamentação mais detalhada, ver Michael Kohlhaas - a vitória da derrota.

32 Posteriormente, Kohlhaas aventará a hipótese de aceitar uma indenização monetária pelos cavalos, aparentemente irrecuperáveis ao serem entregues em Dresden. Nesse ponto, porém, os esforços pedagógicos do comerciante já haviam se concretizado.
} 
Até agora, analisou-se a dimensão público-privada do conflito kohlhaasiano com a ordem estabelecida. Mas a declaração da guerra total é, além de uma investida contra a esfera pública de poder, o momento em que vem à tona o desejo de vingança de Kohlhaas. Esses dois movimentos aparecem entrelaçados, compartilhando um mesmo espaço sem se anularem, impossível que é separá-los. Mas a atuação com vistas ao convencimento domina essa perna do enredo, lançando a vingança, manifestada no desejo do comerciante de ver Wenzel von Tronka em pessoa engordando os cavalos, para um segundo plano. Esse desejo de vingança esvanece-se assim que Kohlhaas vê aberta a porta para a retomada do processo judicial, ainda que esse processo não consiga mais se livrar de sua carga vingativa, de sua dimensão privada, portanto. A vingança contra Wenzel von Tronka acabará por se realizar através da via processual, na pena de dois anos de prisão a que o senhor feudal será condenado.

A vingança será, no entanto, o móvel dominante da perna privadopública da novela, do embate entre Kohlhaas e o príncipe eleitor da Saxônia, que transcorre em paralelo com o pedaço do enredo discutido até aqui. Esse segundo segmento inicia-se na cena de Jüterbock, quando o comerciante recebe da cigana o instrumento com o qual realizará a referida vingança, o papelzinho premonitório. O encontro de Kohlhaas com a misteriosa mulher acontece três dias depois (ou um dia depois) de promulgada a "intimação judicial". O fato de essa cena ser narrada em flashback e por duas vezes revela seu caráter "excepcional" na economia da novela, fazendo irromper no mundo racional e público da luta por justiça o desejo irracional e privado da vingança. Fazendo surgir no mundo hodierno da disputa por dois cavalos o objeto mágico na forma do papelzinho. Fazendo com que o enredo, caracterizado por marcações temporais rígidas, sofra um abalo temporal e volte no tempo por duas vezes, para realizar o mesmo percurso. A novela foi desde sempre uma novela natural-sobrenatural, histórico-mítica; e o texto kleistiano realizará a façanha de encaixar essas duas dimensões de uma forma harmônico-desarmônica ${ }^{33}$. Mas é na cena de Jüterbock que mito e magia surgem ostensivamente. Nela, a cigana, que, sintomaticamente, aparece em dois momentos por meio de verbos colocados no presente do indicativo dentro de discursos feitos até então no passado ${ }^{34}$, realizará três previsões. A

\footnotetext{
33 Para uma análise mais detalhada, ver Michael Koblhaas - a vitória da derrota.

34 "Kaum hatte ich [Kohlhaas] [...] das Weib [...] erblickt: da steht sie plötzlich auf ihre Krücken gelehnt, indem sie sich im Volk umsieht, auf; fasst mich [...]", (KLEIST 2005: 119); "Mal havia eu [Kohlhlaas] olhado para a mulher [...]: então ela, apoiada em suas muletas, levanta-se repentinamente, no momento em que ela olha para as pessoas em redor; me pega [...]"; e "Dies [...] abgemacht, erhebt sie sich, verklebt den Zettel mit Lack [...]", (KLEIST 2005: 130); "Feito isso [...], ela se levanta, cola o papelzinho com verniz [...]".
} 
primeira, de "curto prazo", refere-se ao comparecimento, na praça da cidade, de um corço criado em local fechado e longe dali. As duas outras profecias, de "longo prazo", referem-se ao futuro dos príncipes eleitores. Segundo a cigana, o dirigente de Brandenburgo terá um futuro auspicioso. O da Saxônia, não. Quanto a esse segundo, porém, a mulher não revela o conteúdo específico de sua premonição. E o príncipe eleitor da Saxônia ficará obcecado por conseguir o papelzinho confiado pela cigana a Kohlhaas e no qual ela descreve o futuro do dirigente. De posse desse objeto mágico, paradoxalmente, o comerciante poderá escolher. Ao contrário do futuro imediato do corço e do futuro de longo prazo dos príncipes eleitores, o futuro de Kohlhaas estaria em aberto. Mas essa escolha, possibilitada pela obtenção de um objeto que sinaliza a impossibilidade de escolha do dirigente saxão, será aparente.

Quando, no começo da novela, o narrador diz que Kohlhaas havia exagerado em seu "sentimento de justiça"35, referia-se não apenas à causa pública envolvendo os cavalos, mas também à contenda privada a respeito do papelzinho. Ou seja, não somente à "justiça" como também à "vingança". Kleist escreve "Rechtgefübl" e não "Rechtsgefühl", cortando o "s" indicativo da relação de pertencimento ${ }^{36}$. O termo, que seria traduzido se tivesse o "s" como "sentimento de justiça" (Rechtsgefüh), ganha novas dimensões semânticas ${ }^{37}$, significando também "sentimento do direito" (intuição da lei) e "sentimento correto" (intuição correta, intuição da direiteza, intuição da retitude). Kohlhaas carrega em seu peito não uma simples gana de justiça, mas uma justiça calcada na lei e uma justiça calcada na vingança. No termo Rechtgefübl, as esferas pública e privada da contenda kohlhaasiana já aparecem misturadas, bem como se mesclam a vingança e a justiça, a lei e o fato ${ }^{38}$, a emoção e a razão. Trata-se, portanto, de um sentimento estranho, sob a batuta do qual surgem coisas como um "negócio da vingança"39, "a vingança das leis"40 e uma "virtude exagerada"41. Como se Kohlhaas conseguisse, recorrendo a seu estofo afetivo, dizer se algo corresponde ou não ao direito e

\footnotetext{
35 "[...] kurz, die Welt würde sein Andenken haben segnen müssen, wenn er in einer Tugend nicht ausgeschweift hätte. Das Rechtgefühl aber machte ihn zum Räuber und Mörder" (KLEIST 2005: 13); "[...] em suma, o mundo haveria de ter consagrado sua memória, se ele não tivesse exagerado em uma virtude. $O$ sentimento de justiça, porém, transformou-o em ladrão e assassino".

${ }^{36}$ A palavra é citada uma segunda vez na novela e várias vezes na peça "A Família Schroffenstein", de Kleist.

37 "Es heisst im gesamten Text nicht nach dem gängigen Sprachgebrauch Rechtsgefühl, sondern Rechtgefühl, eine Abweichung, die ein umfassenderes Verständnis signalisiert" (BOGDAL 1981: 69); "Em todo o texto, falase não no uso lingüisticamente corrente do sentimento de justiça [Rechtsgefühl, mas em Rechtgefühl, uma variante que sinaliza uma compreensão mais ampla".

38 A lei kohlhaasiana se faz valer em um mundo já talhado à maneira dela.

39 "Geschäft der Rache" (KLEIST 2005: 61).

40 "Rache der Gesetze" (KLEIST 2005: 103).

41 "Auschweifung in der Tugend: welche eine hybride Wortbildung!" (Holz 1962: 120); "Exagero de uma virtude: que construção vocabular mais híbrida!"
} 
se corresponde ou não à retitude ${ }^{42}$. Ou seja, um apelo à emoção com vistas a realizar objetivos racionais. Não é à toa que, ao deparar-se com injustiças, o comerciante vê seu coração palpitar, enrubesce, empalidece ou espuma de raiva. De outro lado, tomado pelo ódio, será capaz de agir com objetividade a fim de garantir o reconhecimento de seus direitos e de realizar sua vingança. Razão e emoção acabam servindo sempre aos fins desse Rechtgefühl, capaz de tudo instrumentalizar. O sujeito tornado autônomo pelo sentimento racional da justiça vingativa acaba se transformando em objeto desse mesmo sentimento, alienando-se, transformando-se em um sujeito-objeto dos fatos que passam pelo filtro daquele sentimento ${ }^{43}$. Os móveis afetivos e racionais desse vingador banalizam-se. As manifestações sentimentais fazem-se de forma padronizada, repetindo-se entre os mais diferentes personagens maquinalmente. Os cálculos racionais realizam-se em nome do ódio, o que lhes empresta "calor" (ou seja, um apelo à razão com vistas a realizar objetivos emocionais).

O Rechtgefühl de Kohlhaas, diz o narrador, equipara-se a uma balança de pesar ouro, o que significa que ele funciona com a precisão de um artefato mecânico apto a dimensionar qualquer coisa segundo uma mesma medida e independente da vontade do comerciante. A lei se aplica sempre, e por aplicarse em todos os casos, não conhece conteúdo positivo. No ensaio kleistiano "Sobre o Teatro de Marionetes", Herr C., ao ser questionado por seu interlocutor a respeito da possibilidade de as marionetes serem movimentadas com graça sem a participação de qualquer "maquinista", ou seja, por meio de um artefato puramente mecânico, primeiro vacila, mas ao final admite haver tal possibilidade ${ }^{44}$. Kohlhaas é essa marionete que se movimenta segundo "forças puramente mecânicas", no caso dele uma lei maleável o suficiente para proferir julgamentos sobre qualquer fato, porém rígida o suficiente para garantir-lhe a constituição como sujeito. Sob o jugo do Rechtgefühl, Kohlhaas percorre os caminhos, medindo tudo por meio desse crivo. Se algo destoa, então é hora de partir para a ação. O mundo deve ser transformado a fim de

\footnotetext{
42 "Vielmehr wird Fühlen - und das ist die spezifisch Kleistische Wendung - zu einem Mittel der Wahrnehmung" (BLÖCKER 1960: 163); "Mais do que isso, o sentir - e isso é a especificidade da virada kleistiana - transforma-se em um meio de percepção".

43 "Er [Kohhlaas] selbst wird zum Objekt des Geschehens" (SKROTZKI 1993: 14); "Ele [Kohlhaas] próprio transforma-se em objeto dos acontecimentos"; "Kohlhlaas ist inzwischen längst nicht mehr Subjekt des Geschehens, sondern zu seinem Objekt geworden" (WIESE 1956: 59); "Nesse ínterim, Kohlhaas não é mais, há muito tempo, sujeito dos acontecimentos, mas transformou-se em seu objeto".

44 "[...] dass ihr [von der Marionetten] Tanz gänzlich ins Reich mechanischer Kräfte hinübergespielt, und vermittelst einer Kurbel [...] hervorgebracht werden könne" (KLEIST 2005: 557); "[...] de modo que a dança delas [das marionetes] poderia ser atirada para o reino das forças mecânicas e ser realizada por meio de uma manivela".
} 
poder ser pesado e medido pela balança do "sentimento de justiça", o único a que Kohlhaas obedece verdadeiramente. Mais uma vez, trata-se de uma lógica abstrata, mágico-natural. Cabe ao comerciante talhar a realidade que o cerca, recorrendo a métodos pedagógicos pacíficos e violentos. $\mathrm{O}$ exercício da vingança e a luta por justiça possuem ambos um caráter "educativo". Kohlhaas, assim como partira para vingar-se de Wenzel von Tronka em meio à luta de convencimento do mundo sobre seus direitos (uma luta, então, público-privada), transforma o exercício da vingança contra o príncipe eleitor da Saxônia em um caso exemplar ${ }^{45}$ (em uma luta privado-pública). O comerciante não deseja apenas eliminá-lo, mas fazê-lo sofrer o máximo possível $^{46}$, distendendo a punição e inscrevendo no corpo do príncipe a lei que ele havia infringido. $\mathrm{O}$ dirigente saxão tornou-se alvo da vingança de Kohlhaas por, em omissão, trair o comerciante, revogando a "anistia". A ofensa de caráter privado (traição), mas com reverberações públicas (a revogação da liberdade de Kohlhaas), opera mais uma vez a mistura entre as duas esferas. A vingança do comerciante não se limita a negar o conhecimento ao nobre e passa por reproduzir na pele do dirigente o que Kohlhaas acredita ter sido imposto a ele. Quando ficou detido em Dresden, o comerciante foi ludibriado ou, em outras palavras, viu-se transformado em objeto de maquinações a que não tinha acesso, a um conhecimento, portanto, que outros detinham e que a ele era negado. Por isso, Kohlhaas precisa ler o papelzinho; mas não pode fazê-lo e continuar vivo sob pena de se ver constrangido a revelar o conteúdo do texto. A pulsão de morte que o comerciante dirigia contra terceiros na porção público-privada da novela volta-se contra ele na parte privado-pública. O "incendiário assassino" transforma-se em suicida. E o gesto final de vingança é realizado à beira da morte.

Ao final da novela, o Rechtgefübl do comerciante se afirmará no mundo, onde desde sempre esteve calcado. O processo de formação do mundo conduzido por Kohlhaas visa antes a fazer surgir nele, com força plena, a lei já

\footnotetext{
45 "Es scheint uns, die Rache weist destruktive wie auch konstruktive Komponenten auf" (LAURS 1980: 1); "Parece-nos que o tema da vingança apresenta componentes destrutivos e também construtivos".

${ }^{46}$ Kohlhaas diz ao homem enviado pelo dirigente saxão para convencê-lo a abrir mão do papelzinho mágico: "'Edler Herr! Wenn Euer Landesherr käme, und spräche, ich will mich, mit dem ganzen Tross derer, die mir das Szepter führen helfen, vernichten - vernichten, versteht Ihr, welches allerdings der grösseste Wunsch ist, den meine Seele hegt: so würde ich ihm doch den Zettel noch, der ihm mehr wert ist, als das Dasein, verweigern und sprechen: du kannst mich auf das Schafott bringen, ich aber kann dir weh tun, und ich wills!"', (KLEIST 2005: 123); "Nobre senhor! Se vosso governante viesse e dissesse, eu quero, junto com o bando todo dos que me ajudam a brandir meu cetro, me aniquilar - aniquilar, vós compreendeis, isso que seria, acima de tudo, o maior desejo que alimenta minha alma: então ainda assim eu the negaria o papelzinho, que tem mais valor para ele que a existência, e diria: tu podes me levar ao cadafalso, mas eu posso te provocar dor, e eu quero fazer isso!"'.
} 
vigente. Não há na novela, assim, uma discussão real sobre se Kohlhaas agiu ou não com justiça ao lutar pelo restabelecimento dos cavalos e pela imposição da vingança contra o príncipe eleitor da Saxônia. O narrador já havia dito, como ficou exposto, que a pretensão judicial do comerciante era justa. E reforçará o veredicto linhas depois. Mais tarde, quando surgir a informação sobre a existência de uma lei aprovada 12 anos antes proibindo a importação de cavalos brandenburgueses pela Saxônia, o assunto, que deveria reverberar juridicamente, passará em brancas nuvens. Além dessa decisão favorável expedida de ofício, a narrativa opera uma transformação sorrateira do "passe livre" em "anistia", absolvendo Kohlhaas de antemão ${ }^{47}$. Kohlhaas esteve sempre anistiado. Sob a garra dessa eterna justiça de aparência legal, que se afirma por meio de um processo jurídico capaz de marcar posições contrárias para apagar-lhes a oposição, o mundo desmancha-se no ar, torna-se antigrav $^{48}$.

$\mathrm{Na}$ materialidade translúcida criada por uma lei rígida de difícil apreensão, a luta por vingança de Kohlhaas, condicionada à rememoração constante, transcorre sob a marca do esquecimento. Na porção privadopública do enredo, há um momento em que o comerciante parece retroceder. Depois de ter a "anistia" cancelada, o comerciante resolve entrar em acordo com Nagelschmidt a fim de, sob a promessa de regressar à guerra, conseguir libertar-se e, enganando o ex-criado, fugir para Hamburgo e dali para mais longe. Preso e convencido de que os cavalos não poderiam ser recuperados (Kohlhaas já havia aventado a hipótese de aceitar uma indenização em dinheiro pelos animais), o comerciante dispõe-se a esquecer tudo e escapar para um lugar onde ninguém o conheça, onde possa reiniciar seu trabalho sem a pecha da derrota e a marca da "litigância de má-fé". Kohlhaas, mergulhado, como sempre, em sua "obstinação errática", sairia então em busca de um aparato governamental que protegesse seus direitos, conforme foi seu plano ao "ingressar" na comunidade da qual continua a fazer parte, ainda que, agora, na condição renovada de pária. $\mathrm{O}$ acaso intervém novamente para puni-lo. $\mathrm{O}$ portador da carta de Nagelschmidt recebida por Kohlhaas havia caído doente no caminho, a carta já era conhecida dos nobres saxões e tudo não passou de uma armadilha montada para incriminar o comerciante. Os fatos levantam-se contra Kohlhaas a fim de relembrá-lo, sempre e de novo, de seus compromissos. Essa rememoração feita por meio da materialidade ambiente,

\footnotetext{
47 Para uma descrição mais detalhada, ver Michael Koblhaas - a vitória da derrota.

48 Termo usado por Herr C., no "Teatro sobre as Marionetes", para referir-se a essa suposta vantagem dos bonecos.
} 
no entanto, aponta já para a porção de esquecimento contida nessa memória. Não é propriamente o sujeito que se lembra, mas as coisas (ou algo). Kohlhaas esquece-se para ser lembrado pelos fatos, que não têm memória. $\mathrm{O}$ leitor acusará a força do golpe. A estratégia do narrador kleistiano passa por um esforço de esquecimento, de apagamento das incoerências e "erros" espalhados pela prosa. Alimentam essa estratégia a extensão relativamente grande do enredo, os longos parágrafos e as longas frases de construção singular, que, apelando excessivamente à lógica, embotam o raciocínio e incentivam o leitor a uma postura passiva (que é também uma postura de esquecimento), o grande número de personagens com nomes parecidos, a rapidez com que transcorre a narrativa, a distância das concatenações factuais $^{49}$ etc. Esses, no entanto, são os móveis mais evidentes, e mais superficiais, da estratégia citada antes. No centro dessa prosa, conforme ficou dito, há uma lógica abstrata capaz de tudo abarcar, mas que, ao fazê-lo, joga fora o que faz de cada ente um ente singular. O que significa dizer que não há, na novela, nada propriamente sobre o que se lembrar. O efeito de indiferenciação ${ }^{50}$ gerado por "Michael Kohlhaas", e por Michael Kohlhaas, é um efeito almejado. Tendo lido a novela, cada um sente-se livre para dizer o que bem entender a respeito dela, atitude essa que não deixa de conter um teor de verdade. Mas uma verdade negativa, carente de conteúdo. O texto kleistiano cria uma liberdade oca - pode-se dizer a respeito dele o que quer que seja, desde que não se pretenda dizer sobre ele nada de substancial. No plano da jornada kohlhaasiana, o comerciante pode ser terrível ou justo ${ }^{51}$, mas não pode é ser apenas um deles. A mobilidade do comerciante pelos espaços sociais e físicos traduz-se na mobilidade pelos conceitos. Se é impossível prender Kohlhaas (e a pena para quem tentar fazê-lo é uma vida infindável de sofrimentos ao término da qual o aguarda a derrocada fatal), tampouco se pode conceituá-lo ou, rigorosamente, lembrar-se dele (atando-o a um evento

\footnotetext{
${ }_{49}$ Por isso, costuma passar despercebido, por exemplo, que o comerciante desferiu e não desferiu o pontapé mortal contra o jovem criado que tirou os cavalos dele de debaixo de uma cobertura em chamas: "[...] hob dieser [Kohlhaas] plötzlich, mit einer fürchterlichen Gebärde, den Fuss, dass der Tritt, wenn er ihn getan hätte, sein [do jovem criado] Tod gewesen wäre" (KLEIST 2005: 64-65); "[...] de repente este [Kohlhaas], com um gesto medonho, levantou o pé, de forma que o golpe, se ele o tivesse desferido, teria sido a morte dele [do jovem criado]"; "Aber alles, was sie [Kunz e Hinz] [...] erfahren konnten, war, dass ein Knecht [...] aus dem brennenden Schuppen, in welchem sie [os cavalos] standen, gerettet, nachher aber auf die Frage, wo er sie hinführen, und was er damit anfangen solle, von dem grimmigen Wüterich [Kohlhaas] einen Fusstritt zur Antwort erhalten habe", (KLEIST 2005: 90); "Mas tudo o que eles [Kunz e Hinz] [...] puderam descobrir foi que um criado [...] os [os cavalos] teria tirado do galpão em chamas nos quais eles estavam, os teria salvado, mas depois, ao perguntar sobre onde deveria levá-los e o que deveria fazer com eles, teria recebido como resposta, do colérico feroz, um chute".

${ }^{50}$ Ulrich BEIL fala em um "efeito de indiferenciação" na novela. Apontamento de aula.

51 "Wie bei Kleist rechtschaffen ist, ist zugleich auch entsetzlich. Beiden lässt sich nicht voneinander trennen" (FÖLDÉNYI 1999: 347); "Da mesma forma como, em Kleist, algo é justo, é também terrível. Não se pode separar um do outro".
} 
ou a uma imagem de um tempo passado). Escapando continuamente das qualificações ao assumir as mais diferentes qualificações ${ }^{52}$, o comerciante, como fizera o narrador, mina o próprio conceito de conceito, algo sem o que não se pode pensar e lembrar. Ao leitor, desse ponto de vista, não cabe propriamente lembrar-se desse enredo e nem meditar a respeito dele, mas simplesmente aceitá-lo. Recebê-lo com sua coerência incoerente, sua magia natural, sua razão sentimental etc. Impossibilitado de lembrar por onde trafega, o leitor percorrerá, junto com a narrativa, os mesmos caminhos várias vezes sem se dar conta disso.

É o que acontece no que diz respeito às tramas privado-pública e público-privada descritas antes. O comerciante realizará por duas vezes o mesmo percurso: o primeiro, público-privado, no qual luta pela recuperação dos dois cavalos, persegue Wenzel von Tronka e obtém a vitória por meio da intermediação de Martinho Lutero; o segundo, privado-público, no qual luta pela manutenção do (para não perder o) papelzinho, é perseguido pelo príncipe eleitor da Saxônia e obtém sua vitória por meio da intromissão da cigana. Os dois enredos repetem-se no paralelismo das ações e dos personagens. O Kohlhaas justiceiro vingativo opõe-se ao Kohlhaas vingador justo. Os cavalos opõem-se ao papelzinho. Lisbeth à Elisabeth. Wenzel von Tronka ao dirigente saxão. A figura austera e paternal de Martinho Lutero, com o qual o comerciante se encontra dentro de um quarto fechado, que repreende Kohlhaas e que exige dele que observe as leis, funciona como intermediário de Kohlhaas com o mundo celestial, opondo-se à figura compreensiva e maternal da cigana, com a qual o comerciante reúne-se pela primeira vez em uma feira ao ar livre e que tenta convencê-lo a usar o papelzinho mágico para salvar sua vida, funcionando como intermediária de Kohlhaas com o mundo da bruxaria, o mundo infernal - a mãe infernal defenderá seu filho ainda que lhe dê o instrumento em nome do qual este desejará a própria morte; o pai celestial condenará seu filho, sugerindo o argumento jurídico sobre o qual se apóia a sentença de morte, ainda que lhe forneça o instrumento por meio do qual vencerá a causa processual. O comerciante racional-raivoso das petições judiciais e das táticas de guerra bem-

\footnotetext{
52 "Nun ist in der Tat auffallend, dass Kohlhaas gerade nicht [...] über einen festen Charakter verfügt, auf den sich seine Handlungen zurückführen lassen. [...] Je nach Situation weist Kohlhaas ein anderes Erscheinungsbild auf" (FISCHER-LiCHTE 1991: 58); "Pois, de fato, é chamativo que Kohlhaas não dispõe [...] de um caráter rígido, ao qual se pode remeter suas ações. [...] A cada situação, Kohlhaas mostra uma nova cara"; "Es gibt nichts, was man nicht über sie [os personagens de Kleist] sagen könnte; andererseits haben sie auch keine Eigenschaft, der man nicht sofort auch eine Verneinungspartikel anfügen könnte" (FÖLDÉNYI 1999: 432); "Não há nada que não se possa falar sobre eles [os personagens de Kleist]; de outro lado, eles não possuem nenhuma característica à qual não se possa prontamente adicionar uma partícula de negação".
} 
sucedidas opõe-se ao comerciante colérico-calculista da vingança pessoal e da execução. Os enredos, além de correrem em paralelo, também se mesclam. O encontro com a cigana só aconteceu porque Kohlhaas saiu em direção a Tronkenburgo para incendiar o castelo; a vingança contra o príncipe eleitor da Saxônia só se completa porque Kohlhaas será executado por ter rompido a "paz pública". Mito e história, céu e inferno, público e privado unem-se para garantir a perpetuidade do mesmo.

O enredo transcorre, como ficou indicado no parágrafo anterior, sob a marca dos duplos. Repetem-se não apenas os enredos e os gestos, mas também os personagens. Kunz e Hinz von Tronka, a cigana e Lutero, a cigana e Lisbeth, Herse e Nagelschmidt, Lisbeth e Elisabeth, os dois príncipes eleitores, Wenzel von Tronka e o príncipe eleitor da Saxônia, o kaiser e o cachorro Kaiser, os dois castelões. O pulular de personas refletidas embaralha as subjetividades, que se transformam em seu duplo naturalmente e pendem para uma unificação duplificada (unindo-se sem se apagarem como entes diferenciados), o que distancia Kleist dos românticos também neste ponto. $\mathrm{O}$ camareiro e o copeiro da corte de Brandenburgo realizam atos que alguém, normalmente, faz sozinho, como quando "dizem" (em uníssono?) a Wenzel von Tronka uma série de $\operatorname{coisas}^{53}$. Antes disso, em dado momento, haviam trocado de cargo $^{54}$. No final da novela, não será possível distinguir entre a cigana e Elisabeth, entre Elisabeth e Lisbeth e entre Lisbeth e a cigana. E não haverá nada de assombroso nisso. De todos os personagens, Kohlhaas, porém, será o mais fecundo quando o assunto é os duplos. Já se falou sobre o vingador justo e o justiceiro vingativo, sobre o Kohlhaas racional-raivoso e o outro, colérico-calculista. O comerciante ainda se duplica na figura de Nagelschmidt. Mas sua principal relação de duplicidade será aquela entre o Kohlhaas-deus e o Kohlhaas-demônio. Desde o parágrafo inicial, o protagonista é mostrado em sua relação com Deus, relação essa que se torna cada vez mais próxima até o comerciante transformar-se, ele próprio, na figura divina. O primeiro nome do mercador, Michael, Miguel, remete tanto ao anjo guerreiro quanto ao sentido da palavra em hebraico, que significa "Quem é semelhante a Deus?", ou "Que é como Deus?"55. Kohlhaas é definido pelo narrador como alguém que vive "no temor a Deus" ("in der

\footnotetext{
53 "[...] sie [Hinz e Kunz] nannten ihn [Wenzel] einen Elenden [...], kündigten ihm an [...] und forderten ihn auf [...]" (KLeIST 2005: 89-90); "[...] eles [Hinz e Kunz] o [Wenzel] chamaram de um miserável [...], o informaram [...], e o instaram a [...]".

54 "Herren Hinz und Kunz, Kämmerer und Mundschenk von Tronka", (KLEIST 2005: 82); "os senhores Hinz e Kunz, camareiro e copeiro von Tronka".

55 (HAMACHER 2003: 6).
} 
Furcht Gottes" $\left.{ }^{\prime 56}\right)$. E no começo de sua jornada, o comerciante contava com 30 anos, a idade de Jesus quando este deu início a suas pregações ${ }^{57}$. Ao investir contra Tronkenburgo, Kohlhaas o fará como "o anjo da justiça" ${ }^{15}$; mais tarde se denominará um "representante do arcanjo Miguel". Em dado momento, o mercador passa a caminhar precedido por 12 homens segurando tochas e uma grande espada de querubim colocada sobre uma almofada de couro vermelha. Ao final do enredo, o comerciante engole o papelzinho mágico, alçando-se à figura de Ezequiel, que ingere um pergaminho sagrado ao receber o chamado que o transformaria em profeta ${ }^{59}$. E, finalmente, Kohlhaas será executado, como o filho de Deus, pouco depois do Domingo de Ramos. O comerciante, no entanto, não mantém uma ligação umbilical somente com as alturas divinas, mas mergulha também nas profundezas demoníacas. Kohlhaas vive a espalhar chamas infernais, reduzindo Tronkenburgo a cinzas e incendiando Wittenberg e Leipzig. Ao invadir o castelo de Wenzel von Tronka, destrói a capela do local e por pouco não ateia fogo na abadia de Erlabrunn, envolvido pelo "inferno da vingança insatisfeita"60. Mais tarde, será chamado de o "dragão que devastava a terra"161. Lutero cumprimenta Kohlhaas ("weich fern binweg $^{\prime \prime 2}$ ) como Jesus cumprimenta o diabo (Mateus 16, 23 e Mateus 7, 23), e a cena remete também à lenda sobre o encontro do clérigo com o demônio ${ }^{63}$. Por fim, é montado sobre os cavalos em nome dos quais o comerciante travava sua luta que o diabo rodava a Saxônia ${ }^{64}$. Kohlhaas é o deus-demônio cuja figura inspira grande respeito e temor. É a entidade que com um único chute é capaz de, não apenas escancarar portas, mas matar. O pé que o leva de um canto a outro é o mesmo que lhe confere o poder de assassinar alguém com uma patada. O comerciante alça-se a uma estatura celestial-infernal correndo mundo com a cápsula mágica no peito e a espada da justiça nas mãos. E essas dimensões não permanecem estanques na unidade fraturada que formam. O comerciante, como se tentou demonstrar neste artigo, recorre ao terror para realizar a justiça e mostra-se justo ao praticar atos terríveis. $\mathrm{O}$

\footnotetext{
56 (KLEIST 2005: 13).

57 "[Dieser ausserordentliche Mann - Kohlhaas - würde] bis in sein dreissigstes Jahr. Beginn einer Reihe von Anspielungen auf Christus, der nach Lk. 3,23 mit etwa dreissig Jahren erstmals öffentlich aufgetreten sein soll" (HAMACHER 2003: 8); "[Esse homem excepcional - Kohlhaas - seria] até seus 30 anos: começo de uma série de alusões a Cristo, que, com cerca de 30 anos, segundo Lucas 3,23, teria pregado abertamente pela primeira vez".

58 "Der Engel des Gerichts" (KLEIST 2005: 53).

59 (HAMACHER 2003: 54).

60 "in die Hölle unbefriedigter Rache" (KLEIST 2005: 67).

61 "den Drachen, der das Land verwüstete" (KLEIST 2005: 69).

62 (KLEIST 2005: 77).

${ }^{63}$ Essas observações são feitas por FISCHER-LiCHTE.

64 "Pferden [...] auf welchen der Teufel durch Sachsen ritt [...]" (KLEIST 2005: 93); "os cavalos [...] sobre os quais o demônio cavalgava pela Saxônia".
} 
excesso da sanha justiceira torna-o terrível; e o caráter terrível de seus atos (de guerra e de vingança) transformam-no em alguém justo.

Kohlhaas, que transitará por toda a escala mítico-social da novela ${ }^{65}$, é o Messias vindo no final dos tempos para punir os pecadores e recompensar os que obedecem à lei ${ }^{66}$. Grande parte das alusões bíblicas constantes da novela fazem remissão ao Apocalipse ${ }^{67}$. O filho de Deus volta ao mundo para, ao fim e ao cabo, consumar a lei que já estava posta desde o começo dos tempos, mas uma lei demoníaca ${ }^{68}$. Se Kohlhaas está mergulhado no "inferno da vingança" e se, depois, precisa submeter-se à "vingança da lei", então o mundo da lei é um mundo infernal. O paraíso fechado do texto "Sobre o Teatro de Marionetes" ${ }^{69}$ esteve sempre aberto - e Kohlhaas, que se faz acompanhar mais de uma vez pela espada do querubim, é, foi e será o querubim. Na cena derradeira da novela, quando o comerciante ouve o veredicto favorável a sua causa e os cavalos ressurgem vindos do reino da morte, Kohlhaas realizará, por meio de sua execução, seu último ato de justiça e de vingança. Neste momento, deus e demônio, justiça e vingança, sujeito e objeto ${ }^{70}$, vida e morte confundem-se totalmente e o tempo paralisa-se, unindo passado e presente em um emaranhado inextricável:

\footnotetext{
${ }^{6}$ Do homem terrível (o dragão, o demônio) a deus (morto depois do Domingo de Ramos), passando pelas condições de pária, de servo (ao aliar-se ao "populacho" sem pão para investir contra a nobreza da Saxônia), de burguês, de clérigo (o representante do arcanjo Miguel) e de nobre (ao exercer, com pompa de ares feudais, o comando de suas forças bélicas; ao enterrar a mulher como princesa; ao legar a seus filhos um futuro de nobres). Diz LINDER: "Oben und Unten fallen als räumliche und soziale Kategorien in Kohlhaas zusammen" (LINDER 2000: 150); "Superior e inferior coincidem em Kohlhaas como categorias espaciais e sociais".

66 "Er [Kohlhaas] führt seine Rachekrieg in einem apokalyptischen Bewusstsein; die Partei der Guten und die Partei der Bösen sind nach seiner Meinung unerbittlich voneinander geschieden" (WIESE 1956: 56); "Ele [Kohlhaas] trava sua guerra vingadora sob uma consciência apocalíptica; o lado dos bons e o lado dos maus estão, segundo a opinião dele, inexoravelmente separados um do outro".

${ }^{67}$ Segundo HAMACHER, a menção aos "sete cavaleiros" ["sieben", (KLEIST 2005: 63)] com os quais Kohlhaas invade Tronkenburgo é o "Beginn der apokalyptischen Anspielungen, die das Geschehen auf eine eschatologische Ebene heben", (HAMACHER 2003: 17); "começo das imagens apocalípticas, que elevam os acontecimentos a um nível escatológico". A menção ao número sete também antecipa a união, em Kolhhaas, de deus com o demônio: "Sieben ist sowohl die Zahl der Engel vor dem Thor Gottes (Off. 8,2 und 15,1) als auch der Häupter des Drachen (Off. 12,3)" (FISCHER-LiCHTE 1991: 36); "Sete é ainda o número de anjos diante do Portão de Deus (Apocalipse 8,2 e 15,1) e também o número de cabeças do dragão (Apocalipse $12,3) "$.

68 "[...] o Messias é a figura com a qual as grandes religiões monoteístas procuraram solucionar o problema da lei e [...] sua vinda significa, tanto no judaísmo quanto no cristianismo e no islã xiita, o cumprimento integral da lei" (AgAMBEN 2004: 63).

69 "Doch das Paradies ist verriegelt und der Cherub hinter uns" (KLEIST 2005: 559); "O paraíso está realmente fechado e o querubim ficou para trás". Diz BLÖCKER: "Dann läuft Kleists Lebensvorstellung auf ein Jenseits im Diesseits hinaus. Dann muss das Paradies sich schon in irdischen Leben beweisen, und ein Mann wie Michael Kohlhaas trägt dann allerdings einen Heiligenschein" (BLÖCKER 1960: 64); "Então a representação da vida para Kleist resulta em colocar o além no aqui e agora. Então o paraíso precisa se afirmar já na vida terrena, e então um homem como Michael Kohlhaas carrega de fato uma aura sagrada".

${ }^{70}$ Kohlhaas é sujeito da ação jurídica que vence e objeto da pena de morte à qual se submete.
} 
Koblhaas aber, während die bestürzten Begleiter desselben [des Brandenburgischen Kurfürsten] sich herabbeugten, und ihn vom Boden aufhoben, wandte sich zu dem Schafott, wo sein Haupt unter dem Beil des Scharfrichters fiel. ${ }^{71}$

A frase, aparentemente simples, é de difícil tradução por conta de seu caráter fugidio. $\mathrm{O}$ "während" indica ação durativa e, apesar de ligado ao gesto dos acompanhantes do dirigente saxão, contamina o termo principal da oração (que envolve aquele outro, como um invólucro). São quatro as traduções possíveis para o português: "Kohlhaas, porém, enquanto os contrariados acompanhantes do mesmo [do príncipe eleitor de Brandenburgo] se curvavam, e o levantavam do chão, virava-se para o cadafalso, onde sua cabeça caía sob o machado"; "Kohlhaas, porém, enquanto os contrariados acompanhantes do mesmo se curvaram, e o levantaram do chão, virou-se para o cadafalso, onde sua cabeça caiu"; "Kohlhaas, porém, enquanto os contrariados acompanhantes do mesmo se curvaram, e o levantavam do chão, virou-se para o cadafalso, onde sua cabeça caía"; ou (a pior) "Kohlhaas, porém, enquanto os contrariados acompanhantes do mesmo se curvavam, e o levantaram do chão, virava-se para o cadafalso, onde sua cabeça caiu". $\mathrm{Na}$ cena final, o comerciante vira-se para o cadafalso e morre (como era de se esperar); e também (como não era de se esperar) realiza a façanha, a última de tantas, de assistir a sua própria execução. $\mathrm{O}$ arcanjo Miguel mata o dragão, e Kohlhaas revela-se o que sempre foi, o carrasco de si mesmo, vivendo por meio de sua morte ${ }^{72}$, afirmando-se por meio de sua negação ${ }^{73}$. Neste ponto, céu e inferno se encontram no corpo vivo-morto do comerciante - o móvel do processo que desemboca na condenação à morte dele havia sido sugerido por Lutero, o pai celestial (esse móvel é a violação da "paz pública"); o desejo de morte de Kohlhaas alimenta-se da necessidade de punir o príncipe eleitor da Saxônia, da necessidade de ler e nunca divulgar o conteúdo do papelzinho, dado a ele pela cigana, a mãe infernal. Passado e presente, mito e história, magia e natureza, o mundo do além e o mundo terreno ${ }^{74}$, morte e vida passam de um a outro, inapreensíveis, em nome da apoteose derradeira desse sujeito que é, ao mesmo tempo, senhor absoluto e objeto impotente.

\footnotetext{
71 (KLEIST 2005: 141).

72 "Deshalb wird der Tod zu einer das Leben erhöhenden und besiegelnden Macht" (BLÖCKER 1960: 116); "Dessa forma, a morte transforma-se em um poder de elevação e confirmação da vida".

73 "Kohlhaas stirbt zwar, aber als Sieger" (GALLAS 1981: 86); "Kohlhaas morre realmente, mas como vencedor".

74 "Mit seinem [de Kohlhaas] Tod befruchtet er die Welt und bereitet dadurch die Geburt einer nichtdiesseitigen Perspektive vor", (FÖLDÉNYI 1999: 293); "Com sua [de Kohlhaas] morte, ele fecunda o mundo e prepara, através disso, o nascimento de uma perspectiva de além-mundo."
} 
Castro, R. C. P. - Formação de um mundo já posto - Kohlhaas e sua sanha justiceiro-vingativa

\section{Referências bibliográficas}

Agamben, Giorgio. Estado de Exceção. São Paulo, Boitempo Editorial, 2003.

Agamben, Giorgio. Homo Sacer. O poder soberano e a vida nua I. Belo Horizonte, Editora UFMG, 2004.

BLÖCKER, Günter. Heinrich von Kleist oder Das absolute Ich. Berlim, Argon Verlag, 1960.

Bogdal, Klaus-Michael. Heinrich von Kleist: Michael Koblhaas. Munique, Wilhelm Fink Verlag, 1981.

FISCHER-LiCHTE, Erika. Heinrich von Kleist: Michael Koblhaas. Frankfurt am Main, Verlag Moritz Diesterweg, 1991.

FÖLDÉNYI, Lászlo F. Heinrich von Kleist - Im Netz der Wörter. Munique, Matthes \& Seitz Verlag, 1999.

Hamacher, Bernd. Heinrich von Kleist, Michael Koblhaas. Stuttgart, Philipp Reclam, 2003.

Holz, Hans Heinz. Macht und Obnmacht der Sprache - Untersuchungen zum Sprachverständnis und Stil Heinrich von Kleists. Frankfurt am Main/Bonn, Athenäum Verlag, 1962.

Gallas, Helga. Das Textbegehren des 'Michael Kohlhaas' - Die Sprache des Unbewussten und der Sinn der Literatur. Reinbek bei Hamburg, Rowohlt Taschenbuch Verlag, 1981.

KiTTLER, Wolf. Die Geburt des Partisanen aus dem Geist der Poesie. Freiburg im Breisgau, Rombach Verlagshaus, 1987.

KIRCHER, Hartmut. Heinrich von Kleist. Das Erdbeben in Chili/Die Marquise von O... München, Oldenbourg Verlag, 1992.

KLEIST, Heinrich von. Kleist Sämtliche Erzä̈hlungen (organizado por Klaus MüllerSalget). Frankfurt am Main, Deutscher Klassiker Verlag, 2005.

KRETZSCHMAR, Udo. "'Doch das Paradies ist verriegelt...' Betrachtung zu Heinrich von Kleists Welt- und Menschenbild in den Erzählungen 'Michael Kohlhaas', 'Das Erdbeben in Chili' und 'Die Marquise von O..."', in Zwei Vorträge. Heilbronn, Stadtbücherei Heilbronn, 1993.

LAURS, Axel Ilmar. Zum Thema der Rache und der Gesellschaft bei Heinrich von Kleist. Zurique, Massey University Printery, 1980. 
Castro, R. C. P. - Formação de um mundo já posto - Kohlhaas e sua sanha justiceiro-vingativa

LINDER, Joachim. "Mobilisierung und Diabolisierung der Zeichen. Zu Heinrich von Kleists Erzählung Michael Kohlhaas. Ein literaturwissenschaftlicher Kommentar", in Michael Koblhaas. BadenBaden, Nomos Verlagsgesellschaft, 2000.

IDE, Heinz. "Kleist im Niemandsland?". In: MÜLLER-SEIDEL, Walter (Hrsg.). Kleist und die Gesellschaft. Berlim, Erich Schmidt Verlag, 1965.

MÜLLER-SEIDEL, Walter. Versehen und Erkennen - Eine Studie über Heinrich von Kleist. Colônia, Böhlau Verlag, 1961.

SKROTZKI, Ditmar. "Ist Kleist Erzählung vom Kohlhaas wirklich die Geschichte des Rebellen Kohlhaas? Oder: Wie stoppt man den Teufel, der auf zwei Rappen durch Sachsen reitet?", in Zwei Vorträge. Heilbronn, Stadtbücherei Heilbronn, 1993.

Weber, Max. A Ética Protestante e o Espírito do Capitalismo. São Paulo, Centauro Editora, 2001.

WIESE, Benno von. Die deutsche Novelle von Goethe bis Kafka. Düsseldorf, August Bagel Verlag, 1956. 